\title{
PPAR $\gamma$ Regulates Genes Involved in Triacylglycerol Synthesis and Secretion in Mammary Gland Epithelial Cells of Dairy Goats
}

\author{
Hengbo Shi, Jun Luo, Jiangjiang Zhu, Jun Li, Yuting Sun, Xianzi Lin, Liping Zhang, \\ Dawei Yao, and Huaiping Shi
}

Shaanxi Key Laboratory of Molecular Biology for Agriculture, College of Animal Science and Technology, Northwest A\&F University, Yangling, Shaanxi 712100, China

Correspondence should be addressed to Jun Luo; luojun@nwsuaf.edu.cn

Received 9 December 2012; Revised 3 February 2013; Accepted 12 March 2013

Academic Editor: Juan J. Loor

Copyright (C) 2013 Hengbo Shi et al. This is an open access article distributed under the Creative Commons Attribution License, which permits unrestricted use, distribution, and reproduction in any medium, provided the original work is properly cited.

To explore the function of PPAR $\gamma$ in the goat mammary gland, we cloned the whole cDNA of the PPAR $\gamma$ gene. Homology alignments revealed that the goat PPAR $\gamma$ gene is conserved among goat, bovine, mouse, and human. Luciferase assays revealed that rosiglitazone enhanced the activity of the PPAR $\gamma$ response element (PPRE) in goat mammary epithelial cells (GMECs). After rosiglitazone (ROSI) treatment of GMECs, there was a significant $(P<0.05)$ increase in the expression of genes related to triacylglycerol synthesis and secretion: LPL, FASN, ACACA, PLIN3, FABP3, PLIN2, PNPLA2, NR1H3, SREBF1, and SCD. The decreases in expression observed after knockdown of PPAR $\gamma$ relative to the control group (Ad-NC) averaged $65 \%, 52 \%$, 67\%, $55 \%, 65 \%, 58 \%, 85 \%, 43 \%, 50 \%$, and 24\% for SCD, DGAT1, AGPAT6, SREBF1, ACACA, FASN, FABP3, SCAP, ATGL, and PLIN3, respectively. These results provide direct evidence that PPAR $\gamma$ plays a crucial role in regulating the triacylglycerol synthesis and secretion in goat mammary cells and underscore the functional importance of PPAR $\gamma$ in mammary gland tissue during lactation.

\section{Introduction}

Lactation is a process highly demanding of lipid synthesis and transport. Although peroxisome proliferator-activated receptor $\gamma(\operatorname{PPAR} \gamma)$ is known to promote lipogenesis and adipogenesis in adipose tissue [1], its role in the lactating mammary gland is less clear. Many candidate genes that regulate lipid synthesis have been identified during the lactation cycle [2]. Researchers have evaluated the expression profiles of 54 genes associated with bovine milk fat synthesis through various periods during lactation and built a regulatory network [3]. Their data showed that PPAR $\gamma$ might be the main factor that regulates the nuclear transcription factor, sterol regulatory element-binding transcription factor 1 (SREBF1), which also affects the expression of some fatty acid metabolism genes during lactation $[3,4]$.

Much data have been published regarding PPAR $\gamma$ 's role in milk fat synthesis in bovine [5-7], while there is a lack of data on its role in the dairy goat. Whether PPAR $\gamma$ also plays the same critical role in regulation of milk fatty acid synthesis during the lactation process in dairy goat remains to be determined. In the present study, we first identified the sequence of PPAR $\gamma$ in dairy goat mammary tissue and evaluated the activity of the PPRE via luciferase assays. Its function in dairy goat mammary epithelial cells (GMECs) was also investigated through the use of the pharmaceutical ligand rosiglitazone (ROSI) and adenovirus-mediated RNA interference.

\section{Materials and Methods}

2.1. cDNA Cloning. The primers used in the amplification of the goat PPAR $\gamma$ transcript sequence (PPARG) used for cDNA cloning are reported in Table 1. Primers were designed based on the consensus conserved sequences between humans (AB472042) and bovines (BC116098). The PCR reaction was performed with goat mammary epithelial cell cDNA as a template. The cDNA cloning of the $5^{\prime}$ and $3^{\prime}$ UTR was implemented according to the manufacturer's protocols of 
TABLE 1: Primer pairs used in PCR for amplification of goat PPARG from mammary cDNA.

\begin{tabular}{lcr}
\hline Name of fragment & Sequence & Product length \\
\hline PPAR $\gamma$ CDS & Forward: $5^{\prime}$-ATGGTTGACACAGAGATGCCG-3' & 1413 bp \\
& Reversal: $5^{\prime}$-GTAGATTTCCTGTAGAAGTGGGTGG-3' & $516 \mathrm{bp}$ \\
PPAR $\gamma 3^{\prime}$ RACE & Outer: 5'-AAGTAACTCTCCTAAAATACGGCG-3' & $160 \mathrm{bp}$ \\
& Inner: $5^{\prime}$-CCAGAAAATGACGGACCTCAGGCAGA-3' & $750 \mathrm{bp}$ \\
PPAR $\gamma$ 5'RACE & GSP1: $5^{\prime}$-CGGTGATTTGTCTGTCGTCTTTC-3' & $260 \mathrm{bp}$ \\
\hline
\end{tabular}

TABLE 2: Characteristics of shRNA used in the experiment.

\begin{tabular}{lc}
\hline Name of shRNA & \multicolumn{1}{c}{ Sequence } \\
\hline sh500-sense & $5^{\prime}$-GATCC GGAGGACGATCAGATTGAA gagtactg TTCAATCTGATCGTCCTCCTTTTTTC-3' \\
sh500-antisense & $5^{\prime}$-TCGAGAAAAAAGGAGGACGATCAGATTGAA cagtactcTTCAATCTGATCGTCCTCCG-3' \\
Sh614-sense & $5^{\prime}$-GATCCGGATGTCTCATAACGCCAT gagtactg ATGGCGTTATGAGACATCCTTTTTTC-3 ${ }^{\prime}$ \\
sh614-antisense & $5^{\prime}$-TCGAGAAAAAAGGATGTCTCATAACGCCAT cagtactc ATGGCGTTATGAGACATCC G-3' \\
Sh1006-sense & $5^{\prime}$-GATCCGGCTTTGTGAACCTTGACT gagtactg AGTCAAGGTTCACAAAGCC TTTTTTC-3' \\
sh1006-antisense & $5^{\prime}$-TCGAGAAAAAAGGCTTTGTGAACCTTGACT cagtactc AGTCAAGGTTCACAAAGCC G-3' \\
\hline
\end{tabular}

Three shRNAs (numbers stand for their position in cDNA) were designed, and each shRNA was added with restriction sites BamH I and Xho I. The loop domain (lower-case nucleotides) contained a Scal I site.

the 5'RACE system Ver.2.0 (Invitrogen, USA) and $3^{\prime}$ full RACE core set Ver.2.0 (Takara, Japan). The nested gene-specific primers for PPARG, designed based on its open read fragment (ORF), were used for $3^{\prime}$ RACE. Similarly, the nested gene-specific primers (Table 1) were also designed for $5^{\prime}$ RACE. All the PCR fragments were cloned into pMD-19T plasmid vectors (Takara, Japan) and then sequenced at a commercial facility (Invitrogen, Shanghai, China). The PPAR $\gamma$ protein structure was predicted using PHYRE2 (http://www.sbg.bio .ic.ac.uk/phyre2/html/page.cgi? id=index).

2.2. Vector Construction and shRNA. The luciferase vector (pGL3-basic) containing three copies of PPRE was designed as described before [8]. The shRNA sequences were designed using the WI siRNA Selection Program (http://sirna.wi.mit .edu/home.php) and BLOCK-iT RNAi Designer (http:// rnaidesigner.invitrogen.com/rnaiexpress/) using the goat PPAR $\gamma$ gene sequence (HQ589347.1). We selected the highestranked shRNA sequences. Additionally, a BLAST search against all EST sequences in GenBank was performed to ensure that the selected sequences were specific for goat PPAR $\gamma$. Meanwhile, those sequences were selected and synthetized at a commercial facility (Invitrogen, Shanghai, China) with BamH I and Xho I restriction sites suitable for the cloning process (see Table 2). Lastly, three shRNA were generated by heat treatment annealing and constructed into pENTR/CMV-GFP/U6-shRNA. The CDS of PPAR $\gamma$ was subcloned into the $p D s R e d 1-C 1$ plasmid vector between the Xho I and EcoR I restriction sites to generate $p D s R e d 1-C 1-P P A R \gamma$.

2.3. Cell Culture and Treatments. Goat mammary epithelial cells isolated from a Xinong Saanen goat at peak lactation [9] were allowed to grow in $60 \mathrm{~mm}$ culture dishes (NUNC, Denmark) in DMEM/F12 medium (HyClone, China). Routine cultures were incubated at $37^{\circ} \mathrm{C}$ in $5 \% \mathrm{CO}_{2}$ and air. Culture medium was changed every $24 \mathrm{~h}$. Medium was composed of DMEM/F12 with insulin ( $5 \mathrm{mg} / \mathrm{L}$, Sigma, USA), hydrocortisone (5 mg/L, Sigma, USA), penicillin/streptomycin (10 kU/L, Harbin Pharmaceutical Group, China), epidermal growth factor ( $1 \mathrm{mg} / \mathrm{L}$, Sigma, USA), and fetal bovine serum (10\%, Gibco, USA). ROSI (BioVision, USA) was resuspended in DMSO (Sigma, USA) at a concentration of $50 \mathrm{mmol} / \mathrm{L}$. Cells cultured in $60 \mathrm{~mm}$ culture dishes and subcultured to $90 \%$ confluence were treated with $50 \mu \mathrm{mol} / \mathrm{L}$ ROSI and harvested at 0,12 , and $24 \mathrm{~h}$ after treatment to extract total RNA. The 293A cells for preliminary testing of shRNA and generating recombinant adenovirus were cultured in the basal medium containing $10 \%$ fetal bovine serum and $90 \%$ DMEM (Gibco, USA).

2.4. Preliminary Screening of shRNA Sequences. In order to get the most effective shRNAs for targeting PPAR $\gamma$ gene, an experiment was done as follows. $293 \mathrm{~A}$ cells at $80 \%$ confluence in 12 plates were transiently transfected with $1.0 \mu \mathrm{g}$ of three pENTR/CMV-GFP/U6-shRNAs with $p$ DsRed1-C1-PPAR $\gamma$, at a ratio of $3: 2$ using FuGENE HD Transfection Reagent (Roche, Switzerland). The $p D s R e d 1-C 1-P P A R \gamma$ vector also was transfected alone as a control in the same amount as above. All the steps were performed in accordance with the manufacturer's protocol. The GFP fluorescence was monitored by using a Leica fluorescent microscope (DMI4000B, Germany).

2.5. Adenovirus Generation. shRNA expression cassettes with an EGFP reporter gene in the pENTR vector were switched into an adenoviral vector (pAd/PL-DEST) using the Gateway technique (Invitrogen, USA) to generate pAdshRNA vectors. Pac I linearized adenoviral plasmids were transfected into 293A cells to generate the adenovirus. About 
TABLE 3: Characteristics of primer pairs used, amplicon length, and efficiency of reaction in the RT-qPCR.

\begin{tabular}{|c|c|c|c|c|}
\hline Accession $^{\#}$ & Gene & Primer sequence $\left(5^{\prime}\right.$ to $\left.3^{\prime}\right)$ & Product length (bp) & Efficiency \\
\hline JN236219.1 & $A C A C A$ & $\begin{array}{l}\text { Forward: CTCCAACCTCAACCACTACGG } \\
\text { Reversal: GGGGAATCACAGAAGCAGCC }\end{array}$ & 171 & 2.09 \\
\hline JI861797.1 & AGPAT6 & $\begin{array}{l}\text { Forward: AAGCAAGTTGCCCATCCTCA } \\
\text { Reversal: AAACTGTGGCTCCAATTTCGA }\end{array}$ & 101 & 2.17 \\
\hline X91503 & CD36 & $\begin{array}{l}\text { Forward: GTACAGATGCAGCCTCATTTCC } \\
\text { Reversal: TGGACCTGCAAATATCAGAGGA }\end{array}$ & 81 & 2.18 \\
\hline DQ380249.1 & DGAT1 & $\begin{array}{l}\text { Forward: CCACTGGGACCTGAGGTGTC } \\
\text { Reversal: GCATCACCACACACCAATTCA }\end{array}$ & 101 & 2.11 \\
\hline NM_001009350 & $F A B P 3$ & $\begin{array}{l}\text { Forward: GATGAGACCACGGCAGATG } \\
\text { Reversal: GTCAACTATTTCCCGCACAAG }\end{array}$ & 120 & 2.14 \\
\hline DQ915966.3 & FASN & $\begin{array}{l}\text { Forward: GGGCTCCACCACCGTGTTCCA } \\
\text { Reversal: GCTCTGCTGGGCCTGCAGCTG }\end{array}$ & 226 & 2.13 \\
\hline AJ431207 & GAPDH & $\begin{array}{l}\text { Forward: GCAAGTTCCACGGCACAG } \\
\text { Reversal: GGTTCACGCCCATCACAA }\end{array}$ & 249 & 2.16 \\
\hline DQ997818 & $L P L$ & $\begin{array}{l}\text { Forward: AGGACACTTGCCACCTCATTC } \\
\text { Reversal: TTGGAGTCTGGTTCCCTCTTGTA }\end{array}$ & 169 & 2.18 \\
\hline GU332719 & NR1H3 & $\begin{array}{c}\text { Forward: CATCAACCCCATCTTCGAGTT } \\
\text { Reversal: CAGGGCCTCCACATATGTGT }\end{array}$ & 163 & 2.13 \\
\hline HQ846826 & PLIN2 & $\begin{array}{c}\text { Forward: TACGATGATACAGATGAATCCCAC } \\
\text { Reversal: CAGCATTGCGAAGCACAGAGT }\end{array}$ & 203 & 2.16 \\
\hline HQ846827 & PLIN3 & $\begin{array}{c}\text { Forward: GGTGGAGGGTCAGGAGAAA } \\
\text { Reversal: TCACGGAACATGGCGAGT }\end{array}$ & 170 & 1.13 \\
\hline GQ918145 & PNPLA2 & $\begin{array}{l}\text { Forward: GGAGCTTATCCAGGCCAATG } \\
\text { Reversal: TGCGGGCAGATGTCACTCT }\end{array}$ & 226 & 2.24 \\
\hline HQ589347.1 & PPARG & $\begin{array}{l}\text { Forward: CCTTCACCACCGTTGACTTCT } \\
\text { Reversal: GATACAGGCTCCACTTTGATTGC }\end{array}$ & 145 & 2.21 \\
\hline DV935188 & SCAP & $\begin{array}{l}\text { Forward: CCATGTGCACTTCAAGGAGGA } \\
\text { Reversal: TGTCGATCTTGCGTGTGGAG }\end{array}$ & 108 & 2.10 \\
\hline GU947654 & $S C D$ & $\begin{array}{c}\text { Forward: CCATCGCCTGTGGAGTCAC } \\
\text { Reversal: GTCGGATAAATCTAGCGTAGCA }\end{array}$ & 257 & 2.10 \\
\hline HM443643.1 & SREBF1 & $\begin{array}{l}\text { Forward: CTGCTGACCGACATAGAAGACAT } \\
\text { Reversal: GTAGGGCGGGTCAAACAGG }\end{array}$ & 81 & 2.20 \\
\hline
\end{tabular}

Annealing temperature for all primers in this table is $60^{\circ} \mathrm{C}$.

$A C A C A$, acetyl-coenzyme A carboxylase alpha; AGPAT6, 1-acylglycerol-3-phosphate O-acyltransferase 6; CD36, thrombospondin receptor; DGAT1, diacylglycerol acyl transferase 1; FABP3, fatty acid binding protein 3; FASN, fatty acid synthase; GAPDH, glyceraldehyde-3-phosphate dehydrogenase; $L P L$, Lipoprotein lipase; $N R 1 H 3$, liver X receptor $\alpha$; PLIN2, perilipin2; PLIN3, perilipin3; PNPLA2, patatin-like phospholipase domain containing 2; PPARG, peroxisome proliferator-activated receptor $\gamma$; SCAP, cleavage activating protein; $S C D$, stearoyl-CoA desaturase; SREBF1, Sterol regulatory element-binding transcription factor 1 .

${ }^{\#}$ The primer sequences are from bovine.

8 to 10 days after transfection, the recombinant virus was collected and subjected to two rounds of amplification in $293 \mathrm{~A}$ cells. The viral titers were determined in transduced 293A cells through GFP expression as previously described [10-12].

2.6. Luciferase Assays. To assess the degree of PPAR $\gamma$ activation, goat mammary epithelial cells at $80 \%$ confluence in 96-well plates were transiently transfected with $0.08 \mu \mathrm{g}$ of PPRE $\times 3$-Luc reporter plasmid along with a Renilla vector (pRL-TK) as a control using the FuGENE HD transfection reagent at a ratio of $25: 1$. After a $24 \mathrm{~h}$ recovery period in medium, cells were treated with $0,10,25,50$, and $100 \mu \mathrm{mol} / \mathrm{L}$ ROSI. Forty-eight hours later, cells were harvested and lysates were made using reporter lysis buffer (Promega, USA) according to the manufacturer's instructions. Luciferase activity in the cell extract was determined using luciferase assay buffer and luciferase assay substrate according to the manufacturer's protocol (Promega, USA) in a luminometer (BHP9504, China).

2.7. Adenovirus Transduction. Goat mammary epithelial cells at $70-80 \%$ confluence were transduced with adenovirus supernatant at a multiplicity of infection (MOI) of 200. The medium was replaced with fresh medium $6 \mathrm{~h}$ later. The shRNA negative control adenovirus (Ad-NC) was used as a control. Cells were harvested $48 \mathrm{~h}$ after transduction.

2.8. RNA Extraction and Real-Time RT-PCR ( $q P C R)$. Total RNA was extracted from cells using RNAprep pure cell kit (Tiangen, China). The first-strand cDNA of different treatments was synthesized from $0.5 \mu \mathrm{g}$ of purified total RNA using the PrimeScript RT kit (Takara, Japan) according to the manufacturer's instructions. Sufficient cDNA was prepared to 
run all the selected genes (Table 3). Primers were designed to span exon-exon boundaries according to BLAST against bovine genome in order to avoid amplification of genomic DNA using Primer 5.0 software. The specificity of the primers was tested using the same protocol as for qPCR in a simple thermocycler (S1000, Bio-rad, USA), and the PCR product was run in a $15 \mathrm{~g} / \mathrm{L}$ agarose gel. In addition, a dissociation protocol was performed in the RT-qPCR. Only primers with a single band on the agarose gel, a unique peak in the dissociation curve after the RT-qPCR, and devoid of primerdimers were selected. The efficiency of each primer pair was tested using a standard curve as previously described [3]. All the amplicons were sequenced in order to assess the right amplified genes. Characteristics of all primers used in the RTqPCR reaction are described in Table 3. RT-qPCR reactions were performed according to the manufacturer's instructions (SYBR Premix Ex Taq II, Perfect Real Time, Takara, Japan). Glyceraldehyde-3-phosphate dehydrogenase $(G A P D H)$ was selected as an internal control gene [13]. Although we did not verify additional genes as internal controls, GAPDH was used partly because it has been used previously in a goat mammary tissue study [13], and also because it has been widely used as the sole control gene in bovine cell studies [14]. However, we understand the limitation of using a single internal control gene because more reliable data requires the verification and use of at least 3 internal controls [15].

2.9. Western Blot. Whole cell proteins were extracted with RIPA buffer (Solarbio, China) supplemented with PMSF (Pierce, USA). Western blotting was performed using the following primary and secondary antibodies: anti-PPAR $\gamma$ (Abcam, ab19481, Hong Kong, 1:400) and goat anti-rabbit IgG (Tiangen, China, 1:1000). All antibodies were used according to the manufacturer's recommendations. Signals were detected using the chemiluminescent ECL Western blot detection system (Pierce, USA).

2.10. Statistical Analysis. Each treatment was replicated 3 times, and results are expressed as mean $\pm \mathrm{SD}$. Data of RTqPCR was analyzed relative to the control using the $2^{-\Delta \Delta C t}$ method. The statistical significance for ROSI treatment was determined by the ANOVA test using SPSS 19.0 software. Treatment means for shRNA interference were separated using Fisher's least significant difference pair-wise comparisons. Significance was declared at $P<0.05$.

\section{Results and Discussion}

3.1. Molecular Cloning and Sequence Analysis of Dairy Goat PPAR $\gamma$. PPAR $\gamma$ is a member of the nuclear hormone receptor superfamily of transcription factors. It has been fully confirmed in humans and mice that $\operatorname{PPAR} \gamma$ directly regulates adipose cell proliferation, maturation, and differentiation [16, 17]. A potential role of PPAR $\gamma$ in controlling milk fat synthesis also has been reported in bovine due to the increase of its expression between pregnancy and lactation [2] and the increase in expression of genes involved in milk fat synthesis after activation with ROSI
[5]. However, its role, if any, on milk fat synthesis in the mammary gland of the goat remains relatively unknown. In this study, we cloned the dairy goat PPAR $\gamma$ CDS and then used $5^{\prime} \mathrm{RACE}$ and $3^{\prime} \mathrm{RACE}$ procedures to obtain the full-length cDNA. The whole goat PPAR $\gamma$ gene contains a $5^{\prime}$ UTR of $114 \mathrm{bp}$, an ORF of $1428 \mathrm{bp}$, and a $3^{\prime}$ UTR $215 \mathrm{bp}$. Homology alignment (BLASTN) revealed that the dairy goat PPAR $\gamma$ gene (HQ589347.1) shares 90\%, 89\%, 98\% and 98\% identity with human (AB472042), mouse (NM_001127330.1), sheep (NM_001100921), and bovine (BC116098), respectively. Figure 1(a) shows their genetic relationship. The structure prediction using online software revealed that there are two zinc finger structures and a ligand binding domain in the dairy goat PPAR $\gamma$ protein (Figure 1(b)). It was also predicted (PredictNLS online software) that the nuclear localization signal sequence (-KKSRNKC-) of the dairy goat PPAR $\gamma$ gene does not exist in either ends of the peptide chain, but it is present in the protein internal compartment.

3.2. A PPAR Ligand Enhanced Activity of PPAR $\gamma$ Response Element in GMECs. PPAR $\gamma$ is a ligand-dependent nuclear transcription factor, and several unsaturated fatty acids in mammalian tissue are its natural ligands [18]. Binding of ligands to the PPAR $\gamma$ ligand binding domain causes conformational changes in the receptor [16, 19]. Once activated, PPAR $\gamma$ forms a heterodimeric complex with retinoid $\mathrm{X}$ receptor (RXR) and binds to the PPRE upstream of target genes [8]. In the present study, dairy goat mammary epithelial cells were incubated with rosiglitazone, a chemosynthetic ligand, which has a high affinity for PPAR $\gamma$ and enhanced its activity. As shown in Figure 2, treatment with ROSI caused an activation of PPAR $\gamma$ in GMECs. The luciferase levels between the treatment group and the control group (treatment with $0 \mu \mathrm{mol} / \mathrm{L}$ ROSI) were statistically significant $(P<0.05)$. Data also indicated that the activation of the PPAR $\gamma$ by ROSI reached a peak at $50 \mu \mathrm{mol} / \mathrm{L}$ dose.

3.3. Activation of PPAR $\gamma$ by ROSI Affects Expression of Genes Related to Triacylglycerol Synthesis and Lipid Droplets in GMECs. Genes related to de novo fatty acid synthesis (acetyl-coenzyme A carboxylase alpha (ACACA), fatty acid synthase $(F A S N)$ ), desaturation (Stearoyl-CoA desaturase $(S C D)$ ), TAG synthesis (Diacylglycerol acyl transferase 1, $(D G A T 1)$ ) and other genes including fatty acid binding protein 3 (FABP3) and Perilipin2 (PLIN2) were upregulated in adipose tissue of rats [20], humans [21], and bovine mammary epithelial cells [5] treated with ROSI. As summarized in Figure 3, treatment with ROSI increased the expression of $A C A C A, F A S N, S C D, F A B P, L P L$, and also those associated with lipid droplet formation and hydrolysis (PLIN2 and patatin-like phospholipase domain containing 2, PNPLA2), and transcription regulators (SREBF1; liver X receptor $\alpha$, NR1H3) (Figure 3). The significant $(P<0.05)$ increase in gene expression suggests that these genes are putative PPAR $\gamma$ target genes in goat mammary gland. In a previous study, the expression of genes associated with long-chain fatty acid uptake or intracellular activation and transport, including $L P L$, was not affected by ROSI treatment of bovine mammary 


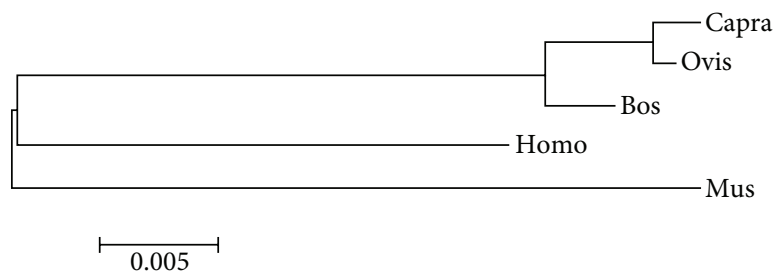

(a)

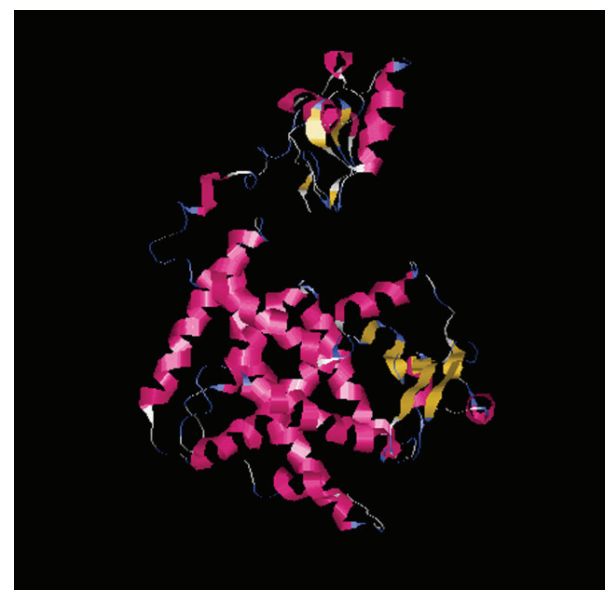

(b)

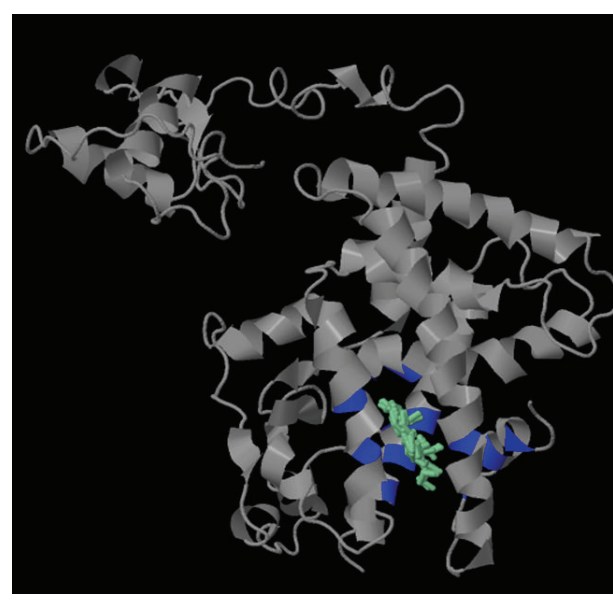

(c)

FIGURE 1: Structure prediction and phylogenetic alignment analysis of the dairy goat PPAR $\gamma$ gene. (a) Phylogenetic tree showing the relatedness of PPAR $\gamma$ CDS sequences of mouse (Mus), human (Homo), bovine (Bos), sheep (Ovis), and goat (Capra). The alignment was performed with ClustalW. The digital " 0.005 " is the genetic ruler. (b) The tertiary structure prediction of goat PPAR $\gamma$. Alpha helices are colored in crimson, beta sheets in yellow, turnings in blue, and irregular curl in white. (c) The ligand binding domain prediction of goat $\operatorname{PPAR} \gamma$. The amino acids involved in the binding sites are colored in blue. The ligands colored in laurel green. In grey is the predicted tertiary structure of the goat PPAR $\gamma$ protein.

cells for $12 \mathrm{~h}$ [5]; however, our results revealed that $L P L$ was upregulated significantly with ROSI treatment but only after $24 \mathrm{~h}$. These contrasting responses may be related at least in part with inherent species differences in the regulatory mechanism via PPAR $\gamma[5,22]$.

\subsection{Preliminary shRNA Screening and Adenovirus Generation.} The GFP protein on the $p E N T R / C M V$-GFP/U6-shRNA vector was used to assess the efficacy of transduction via intensity of green fluorescence inside the cells. The 293A cells were either transfected with only the $p D s R e d 1-C 1-P P A R \gamma$ construct (red fluorescent cells) or cotransfected with both constructs. Once the shRNA enters the cell, if specific for PPAR $\gamma$, it would enhance $p D s R e d 1-C 1-P P A R \gamma$ construct with a concomitant reduction of red fluorescence. In this way, the shRNA efficacy in knocking down PPAR $\gamma$ was assessed by the disappearance of red fluorescence in the cells. As shown in Figure 4, sh1006 and sh614 were more efficient than sh500 to silence PPAR $\gamma$ (Figures 4(b2) and 4(c2)). There was more dsRED fusion protein being coded and detected in the sh500 group (Figure 4(a2)), indicating that sh500 had weaker silencing effect on goat PPARG. This was probably also due to the lower transfection observed for the sh500 construct (Figure 4(a3)).

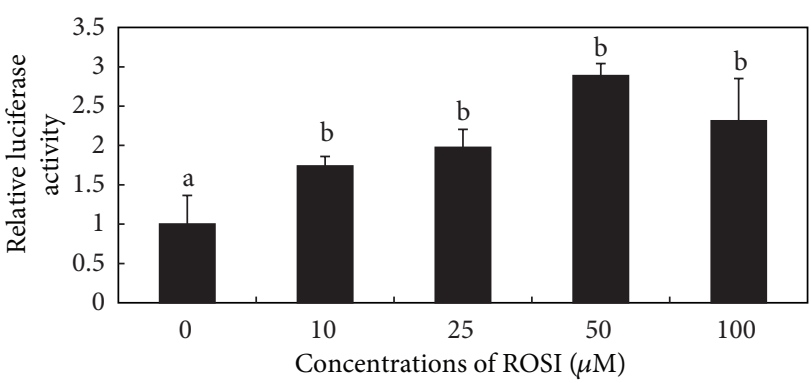

FIGURE 2: ROSI activated the PPAR $\gamma$ response element (PPRE) effectively in GMECs. DMECs were transfected with pGL3-basicPPRE $\times 3$ and $p R L-T K$ vectors. After transfection, cells were treated with different concentration of ROSI. Luciferase and Renilla luciferase assays were performed in triplicate, and the results were expressed relative to the control $(0 \mu \mathrm{mol} / \mathrm{L})$. Luciferase activity data were normalized with Renilla luciferase activity. The data represent mean \pm SD of three independent experiments. ${ }^{\mathrm{b}} P<0.05$ versus the control group.

Although the approach depicted in Figure 4 is not quantitative, it represents a relatively easy way to screen efficient shRNAs. 


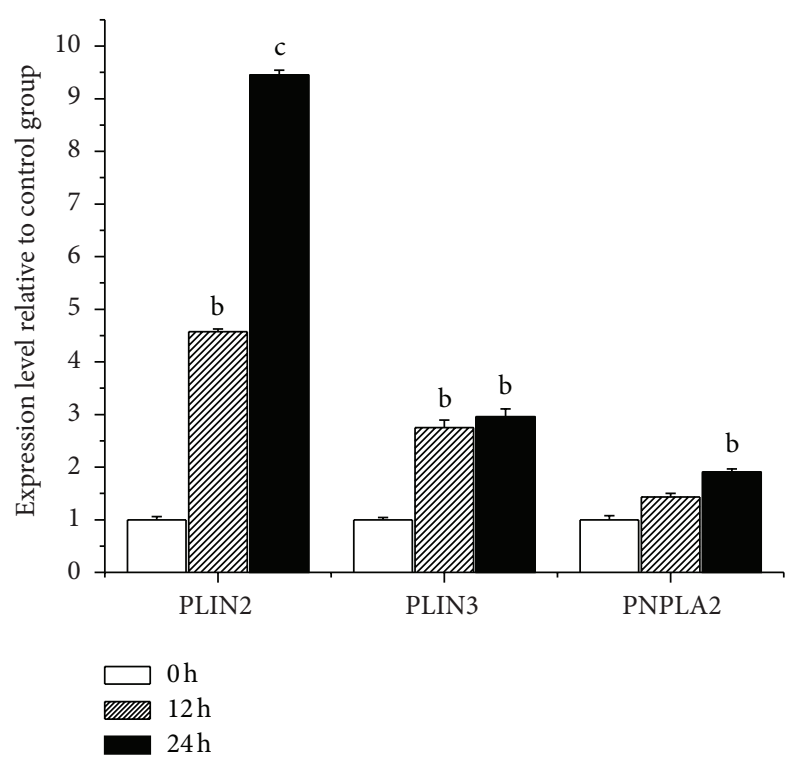

(a)

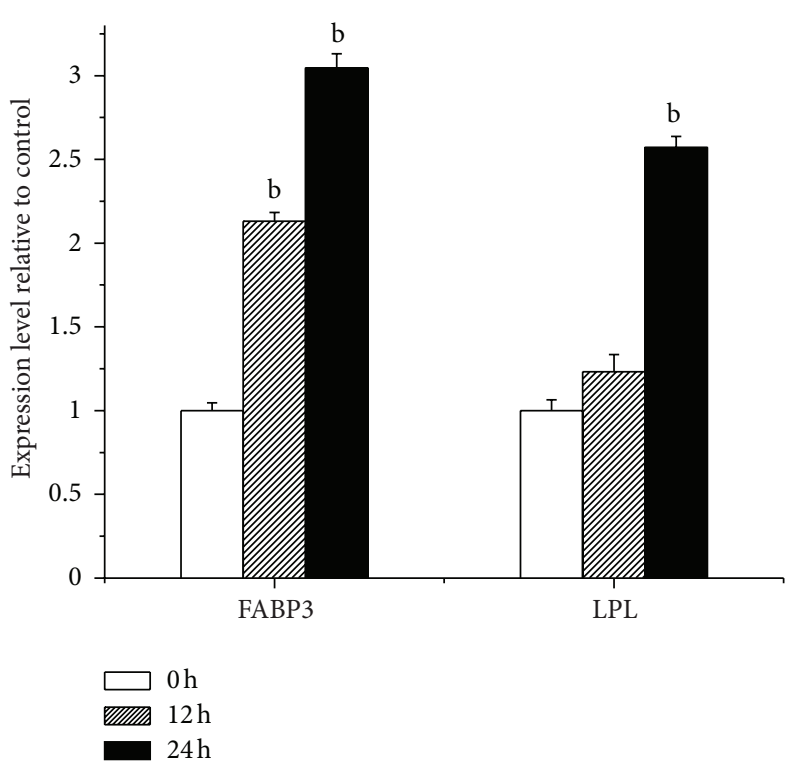

(c)

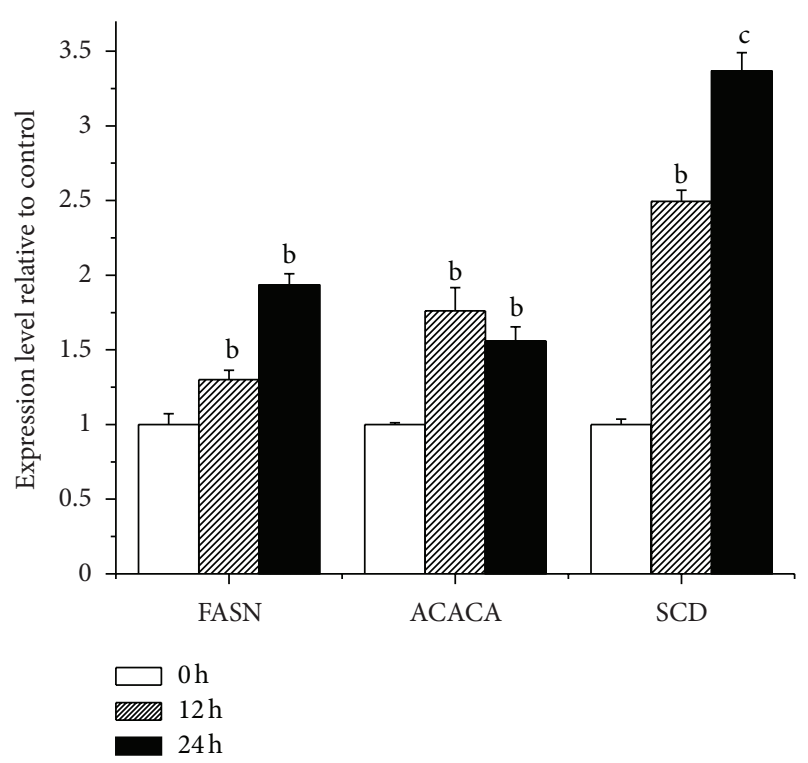

(b)

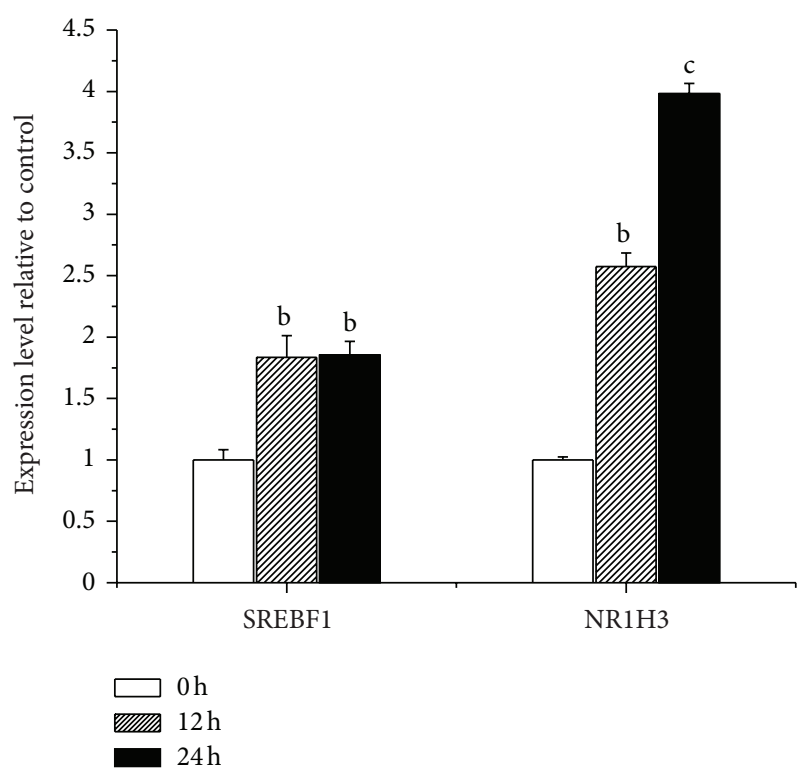

(d)

FIGURE 3: ROSI affects the expression of genes coding for proteins involved in lipid synthesis in GMECs through PPAR $\gamma$ signaling. Dairy goat mammary epithelial cells were treated with ROSI and harvested at 0, 12, and $24 \mathrm{~h}$. (a) Genes related to lipid droplet formation (PLIN2 and PLIN3) and hydrolysis of triacylglycerols (PNPLA2). (b) Genes related to fatty acid synthesis (FASN and ACACA) and desaturation (SCD). (c) Genes related to cellular fatty acid uptake $(F A B P 3, L P L)$. (d) Genes related to regulation of transcription (SREBF1 and NR1H3). The data are mean \pm SD of three independent experiments. ${ }^{b} P<0.05$ versus the control group $(0 \mathrm{~h}) .{ }^{\mathrm{c}} P<0.01$ versus the control group $(0 \mathrm{~h})$.

According to the results of the preliminary screening, sh1006 and sh614 were selected to generate adenovirus Ad-sh614 and Ad-sh1006. Judging by the RT-qPCR and western blot analysis (Figure 5), compared with Ad-sh614 (about 20\%), the Ad-sh1006 (about 60\%) was more efficient in knocking down goat PPARG.
3.5. Knockdown of Goat PPAR in GMECs Affects Expression of Genes Involved in Triacylglycerol Synthesis and Lipid Droplet Formation in GMECs. Based on the above results, the Adsh1006 was selected to block expression of PPARG in GMECs, and expression analysis of genes known to be involved in milk fat synthesis and lipid droplet formation was evaluated (Figure 6). Results demonstrated that FASN (-58\%), ACACA (-65\%), and SCD (-65\%) decreased significantly after PPARG knockdown (Figure 6(a)). With the exception 


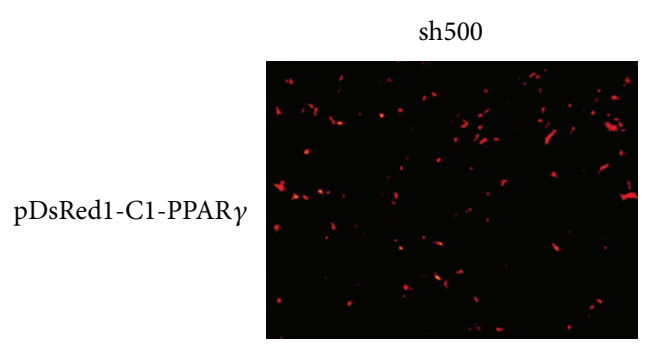

(a1)

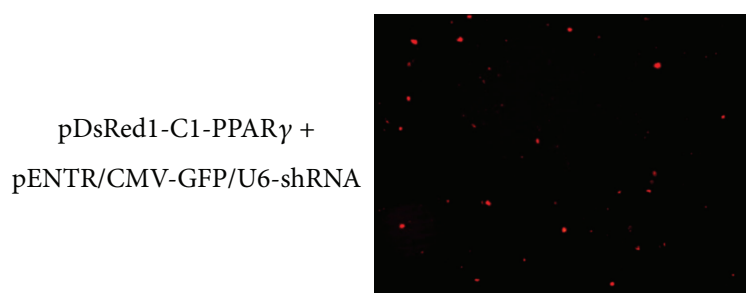

(a2)

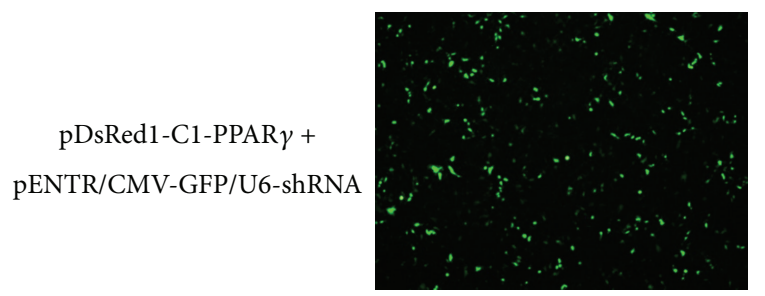

(a3)

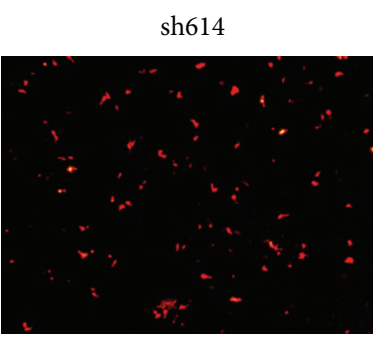

(b1)

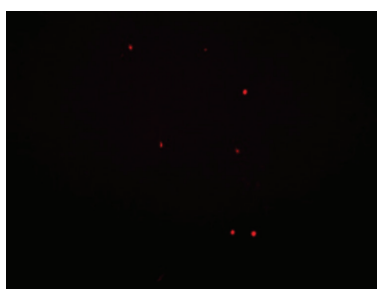

(b2)

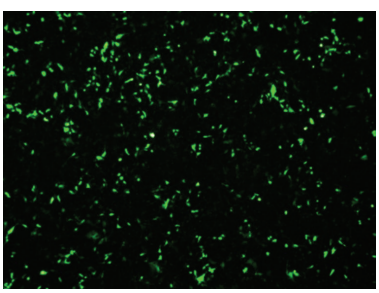

(b3) $\operatorname{sh} 1006$

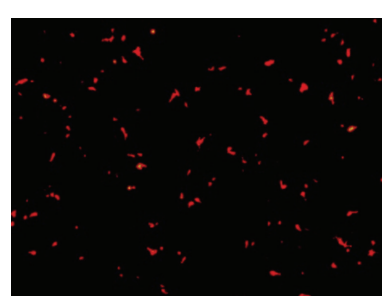

(c1)

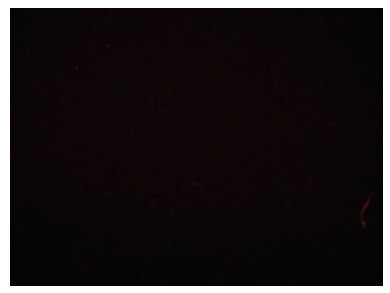

(c2)

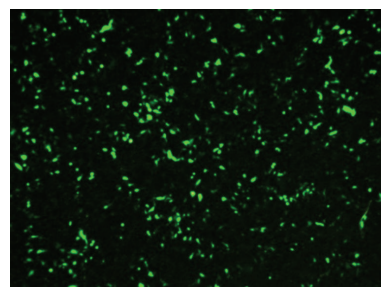

(c3)

FIGURE 4: Efficacy screening of the three designed shRNA via images analysis. pDsRed1-C1-PPAR $\gamma$ vector was transfected as a control ((a1), (b1), and (c1)). The three tested shRNA (sh500, sh614, and sh1006) as $p E N T R / C M V$-GFP/U6-shRNA construct were cotransfected with pDsRed1-C1-PPAR $\gamma$ vector. The transduction efficiency was estimated by the level of green fluorescent protein (GFP) expression ((a3), (b3) and (c3)). Shown are representative images of the PPAR $\gamma$ expression (in red) after a $48 \mathrm{~h}$ cotransfection. (a1), (b1), and (c1) show high transfection and expression of PPAR $\gamma$ construct vector. (a2), (b2), and (c2) show reduction of PPAR $\gamma$ expression after addition of shRNA construct, while (a3), (b3), and (c3) show efficacy of shRNA transfection as shown by the green color (i.e., GFP). Images were obtained by a fluorescence microscope (Leica, DMI4000B, Germany) at 100x magnification. The images clearly show that the sh1006 had the highest effect on PPAR $\gamma$ vector expression (c2).

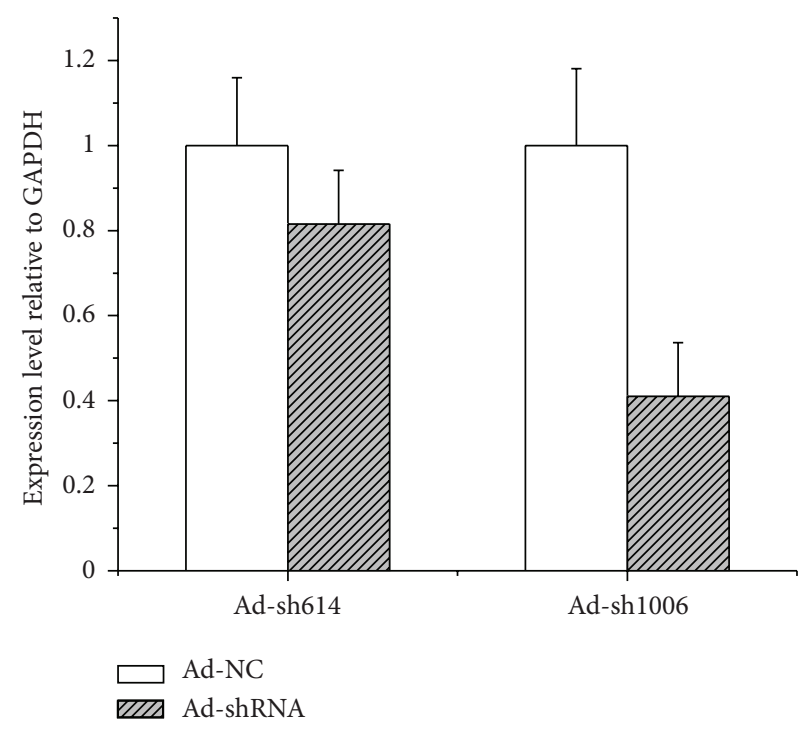

(a)

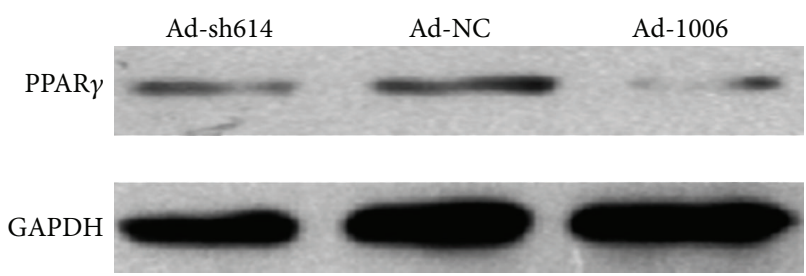

(b)

FIGURE 5: Efficacy screening of the two designed shRNA via RT-qPCR and western blot. The efficiency of Ad-sh614 and Ad-sh1006 (transduced with two adenoviruses at 200 multiplicity of infection for $48 \mathrm{~h}$ ) in decreasing PPARG expression in dairy goat mammary epithelia cells was assessed by RT-qPCR (a) and western blot (b). The data revealed that Ad-sh1006 had the highest knockdown of PPAR $\gamma$ transcript and protein; thus, it was used in the subsequent experiments. 


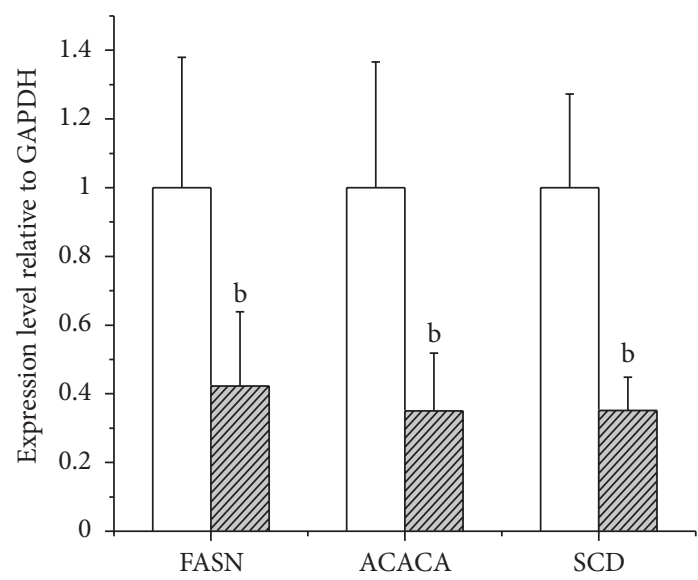

(a)

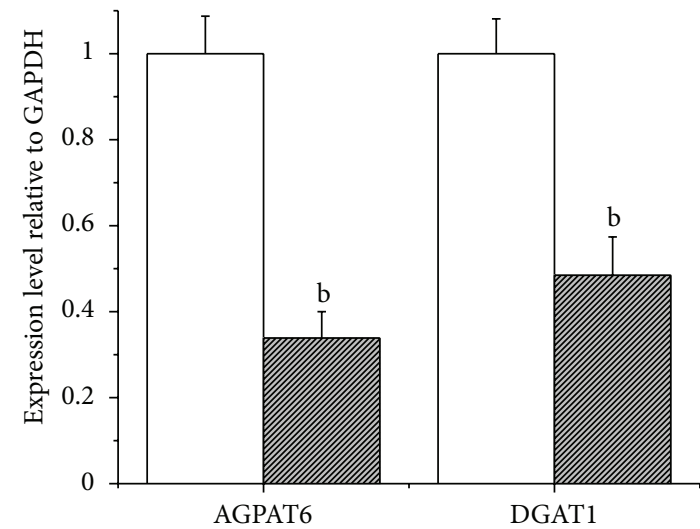

(c)

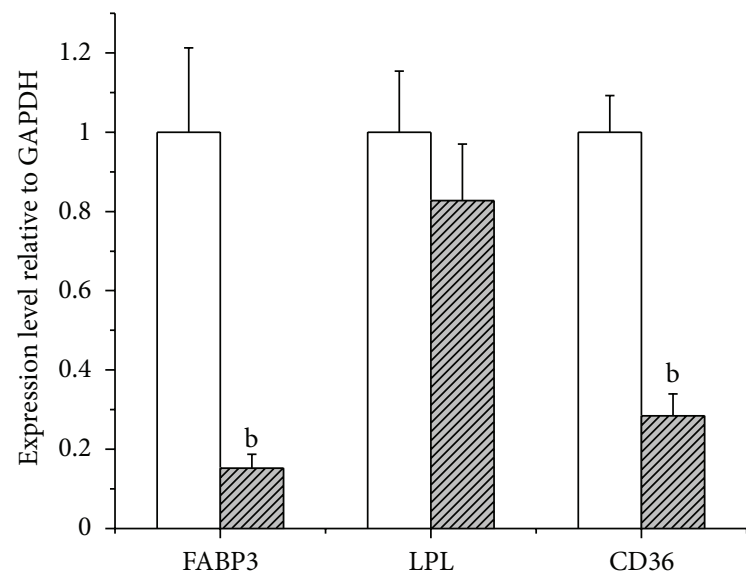

(b)

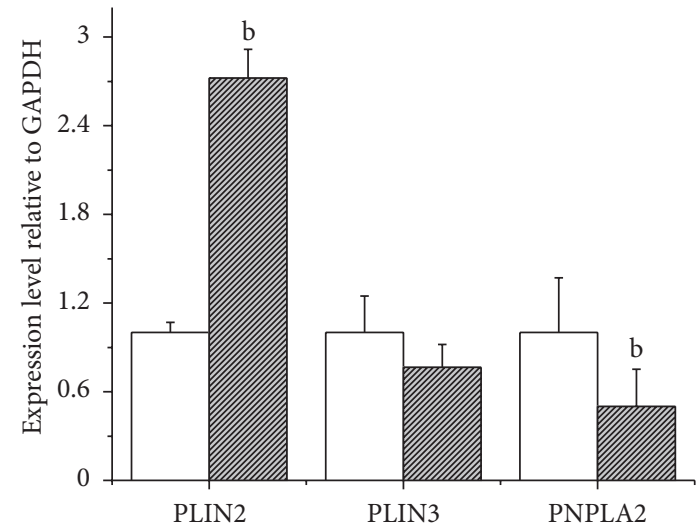

(d)

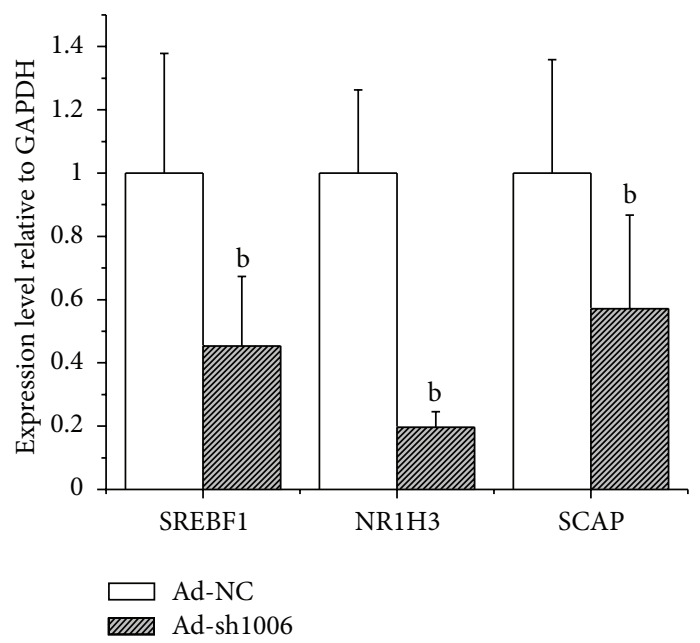

(e)

FIGURE 6: Effect of PPAR $\gamma$ knockdown on genes coding for proteins involved in milk fat synthesis in GMECs. The expression of genes related to fatty acid synthesis (a), cellular fatty acid uptake (b), triacylglycerol synthesis (c), lipid droplet formation and triacylglycerol hydrolysis (d), and transcriptional regulation (e) was assessed in goat epithelial cells (GMECs) after transduction with Ad-sh1006 at $200 \mathrm{MOI}$ for $48 \mathrm{~h}$. The data represent the mean \pm SD of cells transfected with control (Ad-NC) or Ad-sh1006 vector in triplicate per experiment. ${ }^{b} P<0.05$ versus the control group. 
of $S C D$, those data are in agreement with observations in bovine [5] and suggest that PPAR $\gamma$ regulates de novo fatty acid synthesis and desaturation in goat mammary cells.

In bovine mammary cells, SREBF1 has attracted much attention because of its regulation of FASN and SCD expression and the major role played in milk fat synthesis $[6,23]$. PPAR $\gamma$ indirectly regulates SREBP1 protein activity through regulation of the expression of insulin-induced gene 1 (INSIG1) and directly regulates SREBF1 expression in adipose cells of mice [4]. We observed that the expression of $S R E B F 1$ and SCAP decreased by $50 \%$ and $43 \%$ after knockdown of PPARG (Figure 6(e)). The mRNA of NR1H3 gene also was reduced by $75 \%$ when $P P A R G$ was knocked down (Figure 6(e)). Our data agree to a large extent with a previous bovine study, where an increase of SREBF1 expression after ROSI treatment was observed [5]. We speculate that there might be two different signaling networks regulating de novo fatty acid synthesis in ruminant mammary cells. One pathway is under direct regulation of PPAR $\gamma$ and encompasses genes such as LPL, NR1H3, and FABP3 (Figures 6(b) and 6(e)); another is under indirect regulation of PPAR $\gamma$ through SREBF1 and NR1H3 (Figure 6(e)) which would, in turn, participate in upregulation of the transcription of FASN and ACACA [23-25]. Regardless of the specific mechanism, our data support the previous hypothetical milk fat synthesis transcriptional networks proposed for bovine mammary [3]. In agreement with that previous proposal, our data support a complex regulatory network that controls mammary triacylglycerol synthesis in goat mammary cells such that several protein factors serve as putative checkpoints to regulate milk fat synthesis. PPAR $\gamma$ appears to be one of those factors in dairy goats.

PPAR $\gamma$ plays multifaceted roles in the regulation of triacylglycerol synthesis and secretion besides the de novo synthesis of fatty acids. As an adiposity factor, PPAR $\gamma$ is able to regulate triacylglycerol synthesis and deposition and then dominate the process of differentiation of fat cells [26]. In the present study, the mRNA expression of genes related to triacylglycerol synthesis DGAT1 $(-52 \%)$ and AGPAT6 $(-67 \%)$ decreased greatly after infection with Ad-sh1006 (Figure 6(b)), which suggests that PPAR $\gamma$ regulates triacylglycerol synthesis in mammary cells as in fat cells.

Triacylglycerols are deposited in fat cells, while in the mammary cells they are secreted in the form of lipid droplets in milk. To investigate the role of PPAR $\gamma$ in transcription of milk fat globule protein genes, we measured the mRNA expression of PLIN2, PLIN3, and PNPLA2 after PPAR $\gamma$ knockdown (Figure 6(d)). The expression of PLIN2 was largely induced while the expression of PLIN3 and PNPLA2 decreased approximately $24 \%$ and $50 \%$, respectively, in cells transfected with Ad-sh1006, while it is not extremely for PLIN3. Previous data from humans [27] indicated that there is a PPRE on the promoter of the PLIN2 gene; thus, it is considered as a downstream target and would be decreased after PPAR $\gamma$ knockdown. However, our data showed that the expression of PLIN2 had an unexpected increase. Such response might have been caused by compensatory effects of other unidentified transcription factors.
Other data also support the evidence [28] that PPAR $\gamma$ could affect not only the genes related to fatty acid transport, but also genes that control triacylglycerol hydrolysis in goat mammary cells (Figure 6(c)). For instance, expression of PNPLA2 is significantly increased during lactation in bovine mammary tissue [29]. However, judging by differences in milk fatty acid profiles between goat milk and bovine milk [30], goat mammary lipid synthesis differs in some respects from bovine. From a mechanistic standpoints the upregulation of PNPLA2 after PPAR $\gamma$ activation may be functionally related with the unique characteristics of goat milk.

Our data showed that even if there is great similarity between two ruminant dairy species such as goat and cow [5], there are still some inherent differences between them. Such differences may at least in part be caused by different target genes of PPAR $\gamma$ in each species. Attempts to compare in vitro data among studies performed in different laboratories are obviously challenging because of differences in cell culture conditions (e.g., culture medium, absence of prolactin in our study and not in bovine [31]) and also different protocols. The comparisons of data from the present study with data generated in bovine mammary [31] are likely also slanted because of the use in the present study of GAPDH as the only internal control for RT-qPCR normalization versus multiple genes used in the bovine study.

\section{Conclusions}

In the present studies, we cloned the PPAR $\gamma$ gene in dairy goat mammary gland and explored its function in vitro. As proposed in bovine mammary gland, PPAR $\gamma$ plays a multifaceted role in regulating the overall process of fatty acid and triacylglycerol synthesis and secretion. Our overall data indicate that PPAR $\gamma$ in goat mammary plays a role in controlling milk fat synthesis directly or via the activation of the transcription regulators SREBF1 and NR1H3. Together, our data provide strong evidence that PPAR $\gamma$ is the key regulator of milk fat synthesis in ruminants. Hence, controlling PPAR $\gamma$ activation may prove useful in regulating milk fat production in the lactating dairy goat.

\section{Conflict of Interests}

The authors declare that they have no conflict of interests.

\section{Acknowledgments}

This research was jointly supported by the "National Natural Science Foundation of China (31072013)," the "Special Fund for Agro-scientific Research in the Public Interest (201103038)," and "Transgenic New Species Breeding Program of China (2009ZX08009-162B)."

\section{References}

[1] Y. Wan, A. Saghatelian, L. W. Chong, C. L. Zhang, B. F. Cravatt, and R. M. Evans, "Maternal PPAR $\gamma$ protects nursing neonates 
by suppressing the production of inflammatory milk," Genes and Development, vol. 21, no. 15, pp. 1895-1908, 2007.

[2] M. Bionaz and J. J. Loor, "ACSL1, AGPAT6, FABP3, LPIN1, and SLC27A6 are the most abundant isoforms in bovine mammary tissue and their expression is affected by stage of lactation," The Journal of Nutrition, vol. 138, no. 6, pp. 1019-1024, 2008.

[3] M. Bionaz and J. J. Loor, "Gene networks driving bovine milk fat synthesis during the lactation cycle," BMC Genomics, vol. 9, no. 1 , article 366, 2008.

[4] H. R. Kast-Woelbern, S. L. Dana, R. M. Cesario et al., "Rosiglitazone induction of Insig-1 in white adipose tissue reveals a novel interplay of peroxisome proliferator-activated receptor $\gamma$ and sterol regulatory element-binding protein in the regulation of adipogenesis," Journal of Biological Chemistry, vol. 279, no. 23, pp. 23908-23915, 2004.

[5] A. K. G. Kadegowda, M. Bionaz, L. S. Piperova, R. A. Erdman, and J. J. Loor, "Peroxisome proliferator-activated receptor- $\gamma$ activation and long-chain fatty acids alter lipogenic gene networks in bovine mammary epithelial cells to various extents," Journal of Dairy Science, vol. 92, no. 9, pp. 4276-4289, 2009.

[6] O. Mani, M. T. Sorensen, K. Sejrsen, R. M. Bruckmaier, and C. Albrecht, "Differential expression and localization of lipid transporters in the bovine mammary gland during the pregnancy-lactation cycle," Journal of Dairy Science, vol. 92, no. 8, pp. 3744-3756, 2009.

[7] M. Bionaz, K. Periasamy, S. L. Rodriguez-Zas et al., "Old and new stories: revelations from functional analysis of the bovine mammary transcriptome during the lactation cycle," PLoS One, vol. 7, no. 3, Article ID e33268, 2012.

[8] R. Zou, G. Xu, X. C. Liu et al., "PPAR $\gamma$ agonists inhibit TGF$\beta$-PKA signaling in glomerulosclerosis," Acta Pharmacologica Sinica, vol. 31, no. 1, pp. 43-50, 2010.

[9] Z. Wang, J. Luo, W. Wang, W. Zhao, and X. Lin, "Characterization and culture of isolated primary dairy goat mammary gland epithelial cells," Chinese Journal of Biotechnology, vol. 26, no. 8, pp. 1123-1127, 2010.

[10] J. Luo, Z. L. Deng, X. Luo et al., "A protocol for rapid generation of recombinant adenoviruses using the AdEasy system," Nature Protocols, vol. 2, no. 5, pp. 1236-1247, 2007.

[11] P. Ostapchuk and P. Hearing, "Control of adenovirus packaging," Journal of Cellular Biochemistry, vol. 96, no. 1, pp. 25-35, 2005.

[12] D. Gou, T. Weng, Y. Wang et al., "A novel approach for the construction of multiple shRNA expression vectors," The Journal of Gene Medicine, vol. 9, no. 9, pp. 751-763, 2007.

[13] L. Ramunno, G. Cosenza, A. Rando et al., "Comparative analysis of gene sequence of goat CSN1S1 F and N alleles and characterization of CSN1S1 transcript variants in mammary gland," Gene, vol. 345, no. 2, pp. 289-299, 2005.

[14] M. Bionaz, C. R. Baumrucker, E. Shirk, J. P. Vanden Heuvel, E. Block, and G. A. Varga, "Short communication: characterization of Madin-Darby bovine kidney cell line for peroxisome proliferator-activated receptors: temporal response and sensitivity to fatty acids," Journal of Dairy Science, vol. 91, no. 7, pp. 2808-2813, 2008.

[15] M. Bionaz and J. J. Loor, "Identification of reference genes for quantitative real-time PCR in the bovine mammary gland during the lactation cycle," Physiological Genomics, vol. 29, no. 3, pp. 312-319, 2007.

[16] M. Lehrke and M. A. Lazar, "The many faces of PPAR $\gamma$," Cell, vol. 123, no. 6, pp. 993-999, 2005.
[17] P. Tontonoz and B. M. Spiegelman, "Fat and beyond: the diverse biology of PPAR $\gamma$," Annual Review of Biochemistry, vol. 77, pp. 289-312, 2008.

[18] K. L. Houseknecht, B. M. Cole, and P. J. Steele, "Peroxisome proliferator-activated receptor gamma (PPAR $\gamma$ ) and its ligands: a review," Domestic Animal Endocrinology, vol. 22, no. 1, pp. 123, 2002.

[19] G. Lee, F. Elwood, J. McNally et al., "T0070907, a selective ligand for peroxisome proliferator-activated receptor $\gamma$, functions as an antagonist of biochemical and cellular activities," Journal of Biological Chemistry, vol. 277, no. 22, pp. 19649-19657, 2002.

[20] J. M. Way, W. W. Harrington, K. K. Brown et al., "Comprehensive messenger ribonucleic acid profiling reveals that peroxisome proliferator-activated receptor $\gamma$ activation has coordinate effects on gene expression in multiple insulin-sensitive tissues," Endocrinology, vol. 142, no. 3, pp. 1269-1277, 2001.

[21] M. Kolak, H. Yki-Järvinen, K. Kannisto et al., "Effects of chronic rosiglitazone therapy on gene expression in human adipose tissue in vivo in patients with type 2 diabetes," Journal of Clinical Endocrinology and Metabolism, vol. 92, no. 2, pp. 720-724, 2007.

[22] M. Kawai and C. J. Rosen, "PPAR $\gamma$ : a circadian transcription factor in adipogenesis and osteogenesis," Nature Reviews Endocrinology, vol. 6, no. 11, pp. 629-636, 2010.

[23] L. Ma and B. A. Corl, "Transcriptional regulation of lipid synthesis in bovine mammary epithelial cells by sterol regulatory element binding protein-1," Journal of Dairy Science, vol. 95, no. 7, pp. 3743-3755, 2012.

[24] A. Chawla, W. A. Boisvert, C. H. Lee et al., "A PPAR $\gamma$-LXRABCA1 pathway in macrophages is involved in cholesterol efflux and atherogenesis," Molecular Cell, vol. 7, no. 1, pp. 161-171, 2001.

[25] J. W. McFadden and B. A. Corl, "Activation of liver X receptor (LXR) enhances de novo fatty acid synthesis in bovine mammary epithelial cells," Journal of Dairy Science, vol. 93, no. 10, pp. 4651-4658, 2010.

[26] B. B. Lowell, "PPAR $\gamma$ : an essential regulator of adipogenesis and modulator of fat cell function," Cell, vol. 99, no. 3, pp. 239-242, 1999.

[27] B. Fan, S. Ikuyama, J. Q. Gu et al., "Oleic acid-induced ADRP expression requires both AP-1 and PPAR response elements, and is reduced by Pycnogenol through mRNA degradation in NMuLi liver cells," American Journal of Physiology, vol. 297, no. 1, pp. E112-E123, 2009.

[28] B. König, A. Koch, J. Spielmann et al., "Activation of PPAR $\alpha$ and PPAR $\gamma$ reduces triacylglycerol synthesis in rat hepatoma cells by reduction of nuclear SREBP-1," European Journal of Pharmacology, vol. 605, no. 1-3, pp. 23-30, 2009.

[29] M. Bionaz, K. Periasamy, S. L. Rodriguez-Zas, W. L. Hurley, and J. J. Loor, "A novel dynamic impact approach (DIA) for functional analysis of time-course Omics studies: validation using the bovine mammary transcriptome," PLoS One, vol. 7, no. 3, Article ID e32455, 2012.

[30] K. Wilken-Jensen, "Nutrition. Goat's milk can be extremely beneficial in cow's milk allergy," Sygeplejersken, vol. 84, no. 50, pp. 23-24, 1984.

[31] W. E. Ackerman, X. L. Zhang, B. H. Rovin, and D. A. Kniss, "Modulation of cytokine-induced cyclooxygenase 2 expression by PPARG ligands through NFkB signal disruption in human WISH and amnion cells," Biology of Reproduction, vol. 73, no. 3, pp. 527-535, 2005. 


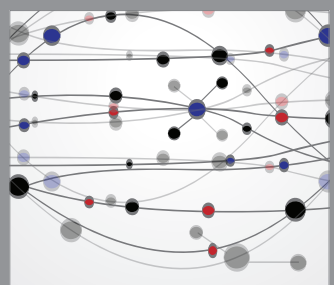

The Scientific World Journal
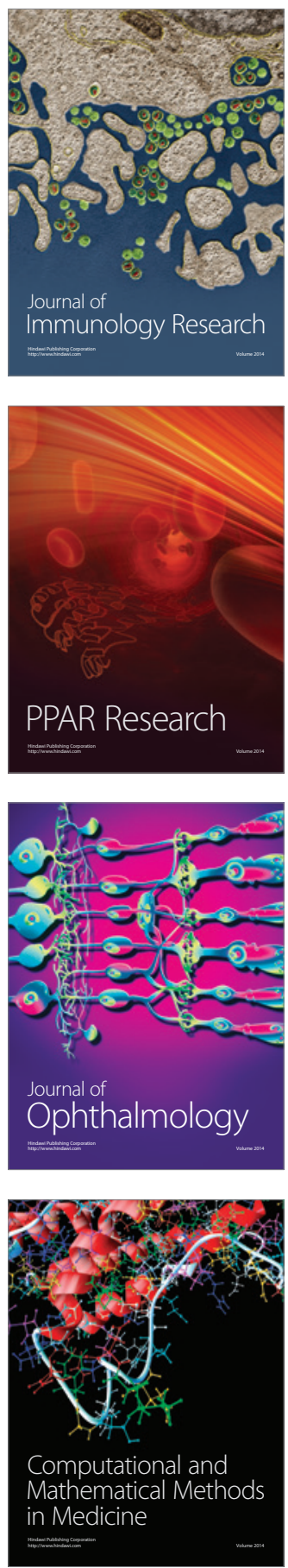

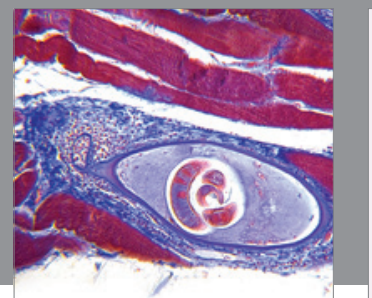

Gastroenterology

Research and Practice
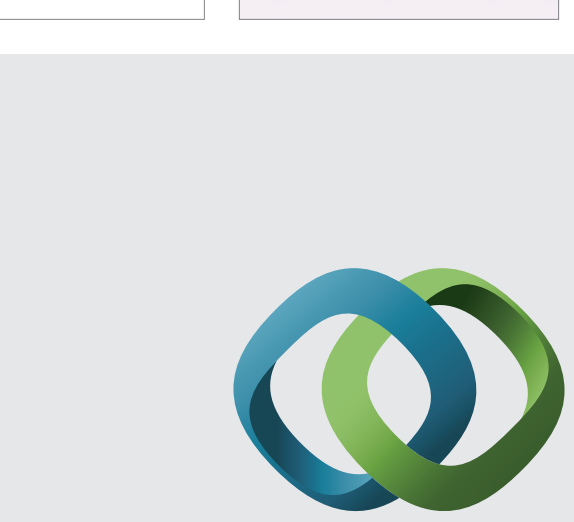

\section{Hindawi}

Submit your manuscripts at

http://www.hindawi.com
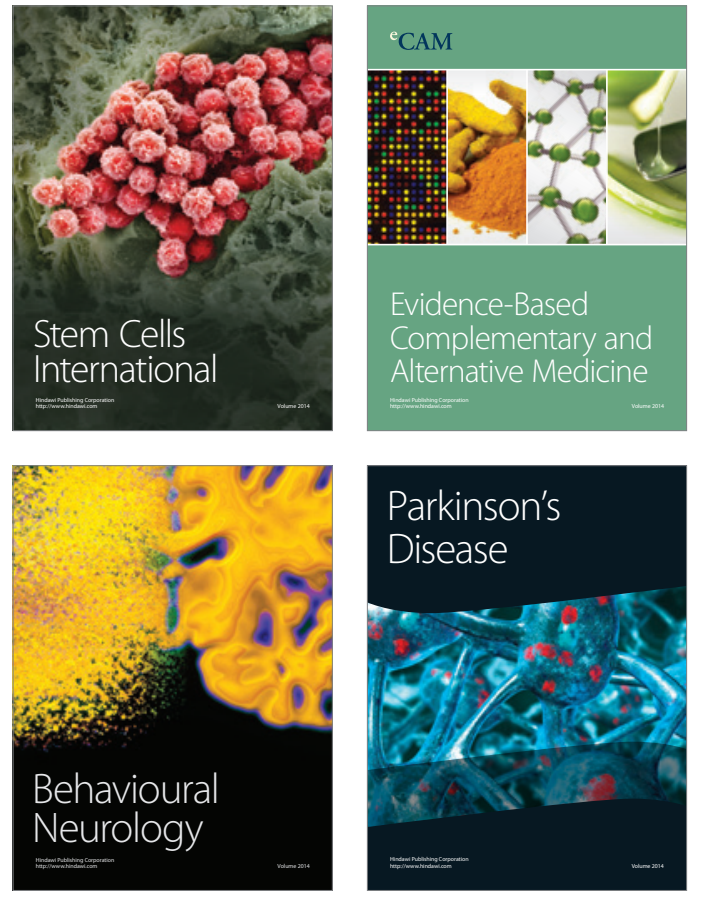
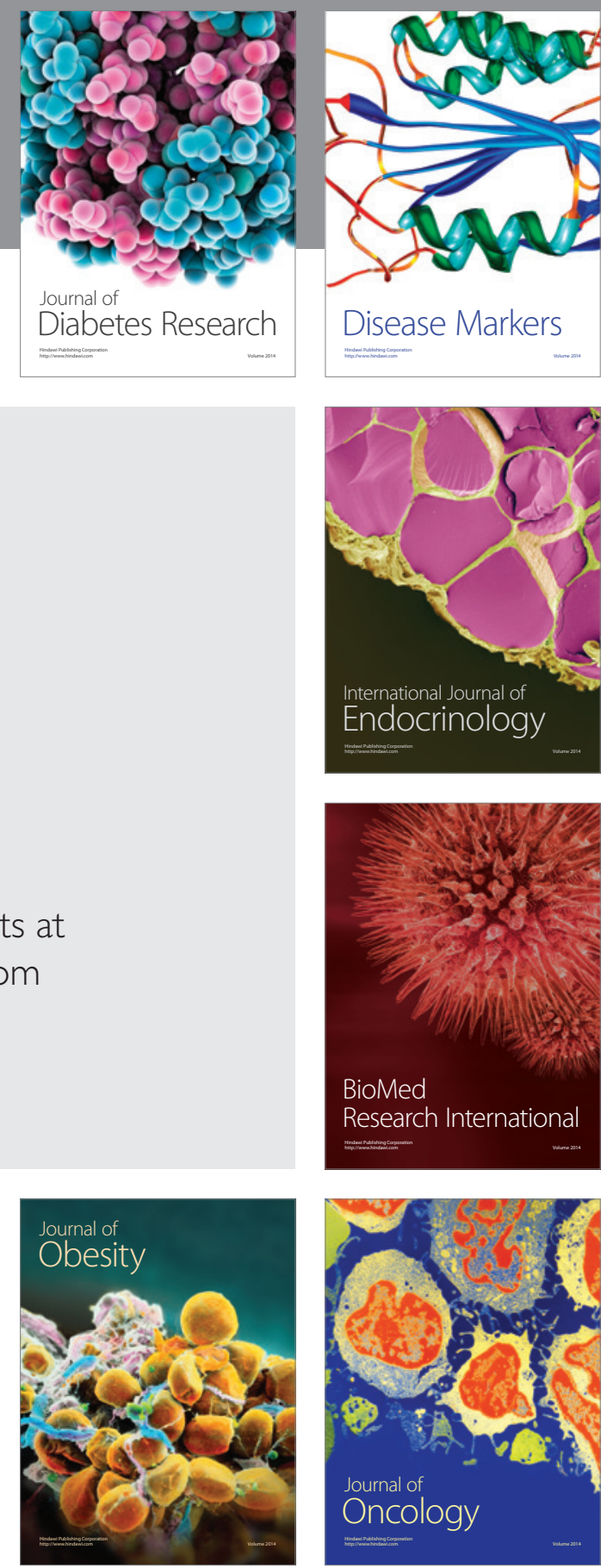

Disease Markers
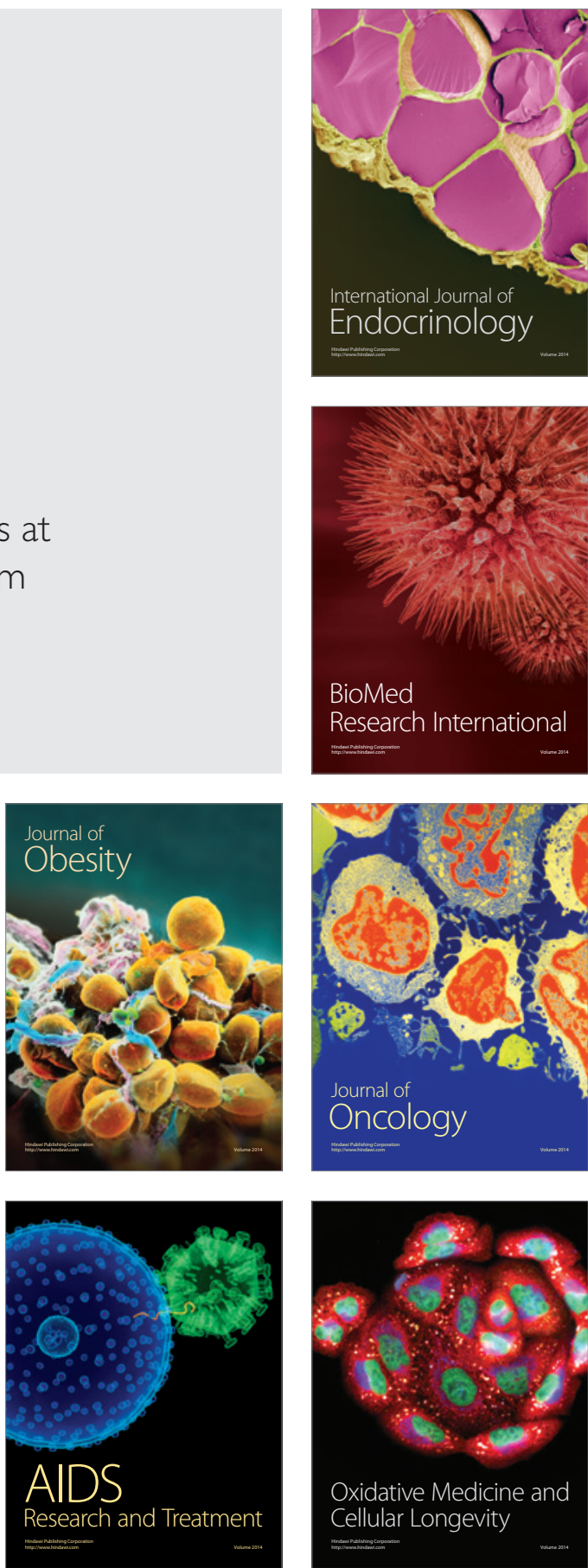